\title{
Spatial distribution of triatomines in domiciles of an urban area of the Brazilian Southeast Region
}

\author{
João Victor Leite Dias, ${ }^{1,+}$, Dimas Ramon Mota Queiroz ${ }^{2}$, Helen Rodrigues Martins², \\ David Eladio Gorla ${ }^{3}$, Herton Helder Rocha Pires², Liléia Diotaiuti ${ }^{1}$
}
${ }^{1}$ Fundação Oswaldo Cruz, Centro de Pesquisas René Rachou, Laboratório de Triatomíneos e Epidemiologia da Doença de Chagas, Belo Horizonte, MG, Brasil ²Universidade Federal dos Vales do Jequitinhonha e Mucuri, Departamento de Farmácia, Laboratório de Doenças Parasitárias, Diamantina, MG, Brasil ${ }^{3}$ Consejo Nacional de Investigaciones Científicas y Técnicas, Instituto Multidisciplinario de Biología Vegetal, Córdoba, Argentina

Reports of triatomine infestation in urban areas have increased. We analysed the spatial distribution of infestation by triatomines in the urban area of Diamantina, in the state of Minas Gerais, Brazil. Triatomines were obtained by community-based entomological surveillance. Spatial patterns of infestation were analysed by Ripley's K function and Kernel density estimator. Normalised difference vegetation index (NDVI) and land cover derived from satellite imagery were compared between infested and uninfested areas. A total of 140 adults of four species were captured (100 Triatoma vitticeps, 25 Panstrongylus geniculatus, 8 Panstrongylus megistus, and 7 Triatoma arthurneivai specimens). In total, $87.9 \%$ were captured within domiciles. Infection by trypanosomes was observed in $19.6 \%$ of 107 examined insects. The spatial distributions of T. vitticeps, P. geniculatus, T. arthurneivai, and trypanosome-positive triatomines were clustered, occurring mainly in peripheral areas. NDVI values were statistically higher in areas infested by $\mathrm{T}$. vitticeps and P. geniculatus. Buildings infested by these species were located closer to open fields, whereas infestations of $\mathrm{P}$. megistus and $\mathrm{T}$. arthurneivai were closer to bare soil. Human occupation and modification of natural areas may be involved in triatomine invasion, exposing the population to these vectors.

Key words: Triatominae - spatial analysis - vector control - urbanisation

Chagas disease represents a major public health issue in Latin American countries. Human infection occurs mainly by vector-borne transmission, in which the protozoan Trypanosoma cruzi (Chagas 1909) is transmitted by infected triatomines (Hemiptera: Reduviidae) (Rassi Jr et al. 2010).

In Brazil, Chagas disease transmission has been associated with people living in rural areas and with poor housing conditions in which triatomines are able to colonise (Coura 2007). The species primarily involved in transmission of T. cruzi in Brazil during the XX century was the domestic insect Triatoma infestans (Klug 1834). This allochthonous species was found in domiciles throughout nearly all the endemic area, although other species of triatomine bugs were of primary importance in large areas of Brazil, especially Triatoma brasiliensis Neiva 1911 and Panstrongylus megistus (Burmeister 1835) (Dias 2007).

After a sustained vector control program, Brazil was certified as free from $T$. cruzi transmission by $T$. infestans in 2006. Nevertheless, native triatomine species are continuously observed invading and colonising artificial environments (Abad-Franch et al. 2013). The expansion

doi: 10.1590/0074-02760150352

Financial support: CNPq, FAPEMIG, FIOCRUZ

+Corresponding author: joao.dias@ufvjm.edu.br

Received 16 September 2015

Accepted 8 December 2015 of human-inhabited areas, including cities, may disturb sites where natural cycles of $T$. cruzi occur, leading triatomines to invade domiciles, and also maintaining synanthropic reservoirs close to dwellings (Coura 2007). In Brazil, reports of infestation by autochthonous triatomines in domiciles of urban areas have increased during recent years (Santana et al. 2011, Maeda et al. 2012, Carvalho et al. 2014, Rodrigues et al. 2014, Ribeiro Jr et al. 2015). The objective of this study was to evaluate the importance of this domestic invasion by triatomines and the spatial pattern of invasion occurrence in an urban scenario of the Southeast Region in Brazil.

\section{MATERIALS AND METHODS}

Study area - This study was performed in the urban area of the municipality of Diamantina, located in the Jequitinhonha Valley region, in the northeast of the state of Minas Gerais, Brazil. This region was one of the most important areas in terms of Chagas disease transmission in Brazil (Dias et al. 1985). In the early 1980s, 11.7\% of the rural population of the Diamantina municipality were infected by T. cruzi (MS/SUCAM/DIDOCh 1980).

The municipality has an area of $3,892 \mathrm{~km}^{2}$, and its population was estimated at 47,803 people in 2014 (MP/ IBGE 2014).

Climate is classified as Cwb, according to the Köppen-Geiger climate classification system (Alvares et al. 2013), and exhibits two distinct seasons: a rainy season that occurs between October-March and a dry season that occurs between April-September. The annual average temperature is $19^{\circ} \mathrm{C}$ and the annual precipitation is approximately 1,400 $\mathrm{mm}$ (Vieira et al. 2010). 
Diamantina is located in the southern area of the municipality, at approximately $1,300 \mathrm{~m}$ above sea level, placed atop a plateau known as the Diamantina Plateau and surrounded by the Cristais Mountains, which are part of the Espinhaço Mountain Range. Diamantina is composed of 25 neighbourhoods. At least 31,654 people live in the city, which contains approximately 20,400 buildings (Diamantina 2009). In this area, soils are shallow and sandy, with a quartzite substrate. Vegetation is characterised by rocky fields known as campos rupestres, which are typical of the Espinhaço Mountain Range (Eiten 1992, Costa 2005, Vasconcelos 2011). Forest fragments are often found associated with watercourses (Diamantina 2009).

Since 1999, the central area of Diamantina has been recognised by the United Nations Educational, Scientific, and Cultural Organization as a World Heritage Site (UNESCO 2000), which implies the existence of specific laws for urban management, leading people to occupy peripheral areas of the city.

Triatomine collection - Triatomines were captured during the activities of entomologic surveillance of Chagas disease, between September 2011-August 2014. People who found a suspect insect in their houses sent it to the municipal health service where specific identification and a parasitological exam of triatomine faeces were performed using optical microscopy. When insects were confirmed to be triatomines, a public health agent visited the house and performed a full entomological evaluation according to the Southern Cone Initiative protocol (OPS 1993).

We verified the species identification of triatomine species and data associated with the insect collection was recorded (house address and geographic coordinates, name of householder, place where the triatomine was found, sex or nymph stage, positivity for trypanosome, and information about who captured the insect - whether it was captured by the house owner or a health professional).

Spatial analysis - Infested houses were geo-referenced with a handheld GPS unit (GPS Map 76S, Garmin ${ }^{\mathrm{TM}}$ ). The geographic coordinate recorded in front of the infested house was considered for analysis. A "shapefile" of the 25 urban neighbourhoods of Diamantina was drawn based on the Brazilian National Health Foundation sketches with the support of a Google Earth ${ }^{\mathrm{TM}}$ scene as a reference.

The pattern of the spatial distribution of different triatomine species and trypanosome-infected insects was evaluated using graphical analysis of univariate Ripley's $\mathrm{K}$-function expressed as an L function. The analysis identifies clustered, randomly, or regularly distributed events in an area; pattern significance may be evaluated by simulations based on complete spatial randomness (Dixon 2002). Visually identified hotspots were calculated by a Kernel density estimator, which is a nonparametric interpolation technique based on the occurrence of events over a region of interest and smoothed by a searching radius (Gatrell et al. 1996).

The spatial analysis of triatomine invasion events was carried out using the K-function included in SPRING 5.2.7 (Câmara et al. 1996), in which we considered distances between zero-1,000 m. Significance was evaluated with 999 simulations considering a significance level of 5\%. A quartic Kernel density estimation function was calculated in
TerraView 4.2.2 (dpi.inpe.br/terraview/) using an adaptive radius, which varies according to the number of events and the extent of the study area (Lagrotta et al. 2008).

We expected that vegetation cover would influence the occurrence of triatomine invasions because of the association between vegetation and the ecotopes of triatomines and their hosts. Vegetation cover [estimated from normalised density vegetation index (NDVI) imagery, see below] was compared between occurrence and nonoccurrence triatomine invasion sites. The coordinates of the infested houses served as the occurrence sites, whereas 150 random points generated over uninfested neighbourhoods served as the nonoccurrence sites.

The NDVI values were calculated from bands 4 (red - wavelength $0.636-0.673 \mu \mathrm{m}$ ) and 5 (near infrared - wavelength $0.851-0.879 \mu \mathrm{m}$ ) of the Operational Land Imager on the LANDSAT 8 satellite. Scene acquisition dates were 25 August 2013 and 28 August 2014 (earthexplorer.usgs.gov/). Atmospheric correction was performed using the dark object subtraction method (Chavez Jr 1988). NDVI values were calculated for each date using SPRING 5.2.7 (Câmara et al. 1996). Because vegetation could vary from year to year due to differences in rainfall, we calculated the difference in NDVI values between dates to evaluate its change throughout two consecutive years. Because the NDVI values showed little change between 2013-2014 (restricted to only a few changed pixels in the image), the most recent image was chosen to evaluate the NDVI in sites where triatomines were both found and not found.

To compare the NDVI values, buffers were drawn surrounding each occurrence and nonoccurrence points with radii of $50 \mathrm{~m}, 100 \mathrm{~m}, 150 \mathrm{~m}, 200 \mathrm{~m}$, and $250 \mathrm{~m}$. The NDVI average for each circle buffer was calculated and compared to triatomine occurrence and nonoccurrence points, by species.

The association between house invasion by triatomines and distance to land cover type was analysed. Land cover was classified into the following three classes according to NDVI values and based on field observations: bare soil (NDVI between 0-0.15), open fields (NDVI between $0.15-0.3$ ), and forest (NDVI $\geq 0.3$ ). Distances between infested or uninfested houses and land cover classes were measured and compared according to species.

A Kruskal-Wallis test followed by Dunn's multiple-comparison tests, with a significance level of 0.05 (GraphPad Prism ${ }^{\mathrm{TM}}$ 5), was used to compare NDVI values with distances to the vegetation cover classes at both triatomine occurrence and nonoccurrence sites.

Ethics - This study was approved by the Ethical Committee of the Federal University of Jequitinhonha e Mucuri Valleys (protocol 520.250).

\section{RESULTS}

A total of 140 adult triatomines of four species were captured between September 2011-August 2014 and referred to the Diamantina health services. Triatoma vitticeps (Stål 1859) was the most frequent (73 $\hat{\jmath}, 27$ ) $)$, followed by Panstrongylus geniculatus (Latreille 1811) $(15 \hat{\jmath}, 10$ 우), P. megistus $(6 \hat{\jmath}, 2$ 우), and Triatoma arthurneivai Lent \& Martins 1940 (5今े, 2ㅇ). 


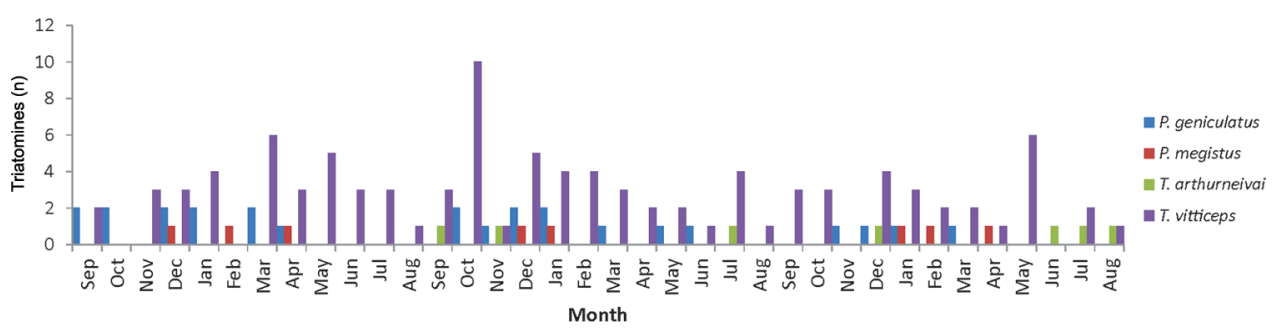

Fig. 1: number of triatomines by species captured in urban area of Diamantina, state of Minas Gerais, Brazil, September 2011-August 2014, according to month.

Among the captured triatomines, examination of infection in 33 insects was not possible because the specimens were dry and therefore did not present intestinal content for analysis. Of a total of 107 examined insects, none of the $P$. megistus (5 examined specimens) and T. arthurneivai (6 examined specimens) were infected; however, trypanosome infections were observed in P. geniculatus (5/13 examined specimens) and $T$. vitticeps (16/83 examined specimens), totalling $19.6 \%$ of the examined insects.

Most of the triatomines were captured inside houses (87.9\%). Infested sites were primarily bedrooms $(33.6 \%)$ and living rooms $(32.1 \%)$, followed by bathrooms $(6.4 \%)$, kitchens (5.7\%), and utility areas (5.7\%). Other locations included back yards $(3.6 \%)$, balconies $(0.7 \%)$, garages $(2.1 \%)$, prison courtyard $(0.7 \%)$, sports courts $(0.7 \%)$, streets $(2.9 \%)$, and walls $(2.1 \%)$. Two cases in which insects $(1.4 \%)$ were captured inside the houses lacked information about where the capture occurred and three (2.1\%) triatomines had no site capture information. Infected $P$. geniculatus were captured in kitchens (2), living rooms (2), and utility areas (1), whereas infected T. vitticeps were captured in bedrooms (6), living rooms (4), walls (2), balconies (1), bathrooms (1), utility areas (1), and streets (1).

Captures occurred in all months, but were more frequent in December and January (Fig. 1). Only one specimen was captured by the public health services agent; all other specimens were captured by house owners who subsequently notified public health. There were 114 infested houses, largely distributed (72\%) among 18 neighbourhoods. In 15 (13.2\%) houses, multiple episodes of infestation occurred - twice in eight houses, three times in five houses, four times in one house, and six times in one house. In five houses, triatomines of two different species were captured - $T$. vitticeps and $P$. geniculatus. Among the infested houses, 112 (98.3\%) were georeferenced, but two had incomplete addresses, which precluded house finding and geo-referencing. All the infested houses were made of brick and had roofs with slab and/or ceramic or asbestos tiles.

Regarding the spatial distribution of infested houses, only P. megistus did not present significant clustered distribution patterns by K-function analysis (Fig. 2A-D). Positivity for trypanosomes was clustered as well (Fig. 2E). The distributions of $P$. geniculatus, T. arthurneivai, and $T$. vitticeps exhibited an evident peripheral pattern (Fig. 3).
NDVI values were significantly higher in areas infested by $P$. geniculatus and $T$. vitticeps than in areas infested by other species or uninfested. No significant differences were observed between the NDVI values for $P$. megistus and T. arthurneivai infested areas and uninfested areas (Fig. 4).

Considering land cover, the area exhibited a highly heterogeneous pattern. However, some triatomine species were observed closer to specific land cover than others. In contrast to other species, houses infested by $T$. vitticeps were further away from forest fragments than uninfested areas. Houses infested by $T$. vitticeps and $P$. geniculatus were located significantly closer to open fields than uninfested random points. For these two species, an inverse trend was observed in areas surrounded by bare soil (Fig. 5).

\section{DISCUSSION}

Although originally associated with rural areas, reports of infestation by triatomines are increasing in urban areas, including those species known to be involved in $T$. cruzi transmission to humans (Guzman-Tapia et al. 2007, Santana et al. 2011, Maeda et al. 2012, Carvalho et al. 2014, Rodrigues et al. 2014, Ribeiro Jr et al. 2015).

Winged adult specimens of four triatomine species were captured throughout the year in the domiciles of an urban area of Diamantina. Two of these species were found naturally infected by trypanosomes. It is possible to infer that these trypanosomes were $T$. cruzi, what is supported by Reis et al. (2013), which detected kDNA of this parasite in faeces of triatomines from this region, including some of the insects in the present study.

T. vitticeps was the most frequently captured triatomine in Diamantina and was highly infected by trypanosomes, as also observed in other parts of Brazil (Dias et al. 1989, dos Santos et al. 2005, 2006a, 2014, Souza et al. 2010). Even with its low vector capability (dos Santos et al. 2006b), some reports incriminate the species in the transmission of T. cruzi to humans (Lorosa et al. 2003, 2008, Sangenis et al. 2015), pointing out the importance of a close entomological surveillance on this species in its areas of occurrence.

In contrast to findings from other areas (Dias et al. 1989, Gonçalves et al. 1998, 2000, Leite et al. 2010), more males than females of $T$. vitticeps were captured in Diamantina. This discrepancy may be due to population 

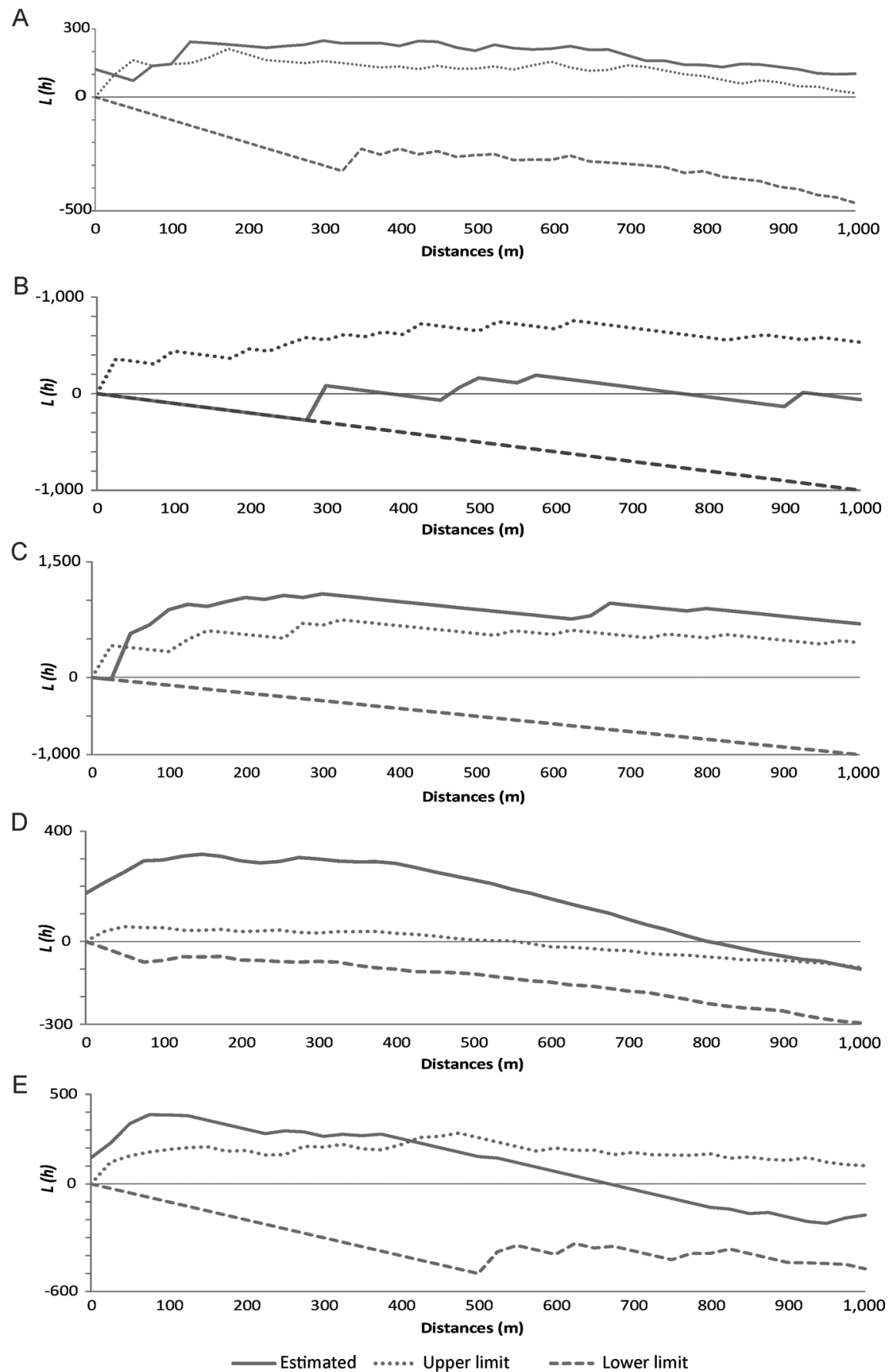

Fig. 2: K-function expressed as L-function values according to distances between buildings infested by triatomines in the city of Diamantina, state of Minas Gerais, Brazil, September 2011-August 2014. A: Panstrongylus geniculatus; B: Panstrongylus megistus; C: Triatoma arthurneivai; D: Triatoma vitticeps; E: triatomines infected by trypanosomatids.

differences driven by environmental characteristics that may influence insect dispersal. Gürtler et al. (2014) observed an influence of weight/length ratio on the flight capability of females of T. infestans that was not observed for males. In addition to this, these authors demonstrated that females, in sites with constant food avail- ability, were less prone to fly, and this behaviour may be associated with the maintenance of a high weight/length ratio. Most findings of $T$. vitticeps are reported from areas covered by the Atlantic Forest [states of Espírito Santo (ES) and Rio de Janeiro], but Diamantina is placed within a Cerrado biome, surrounded by rocky fields. 
A

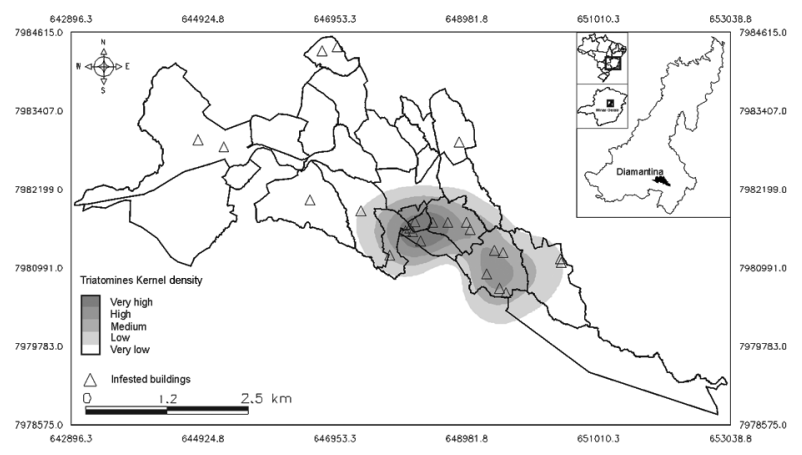

C

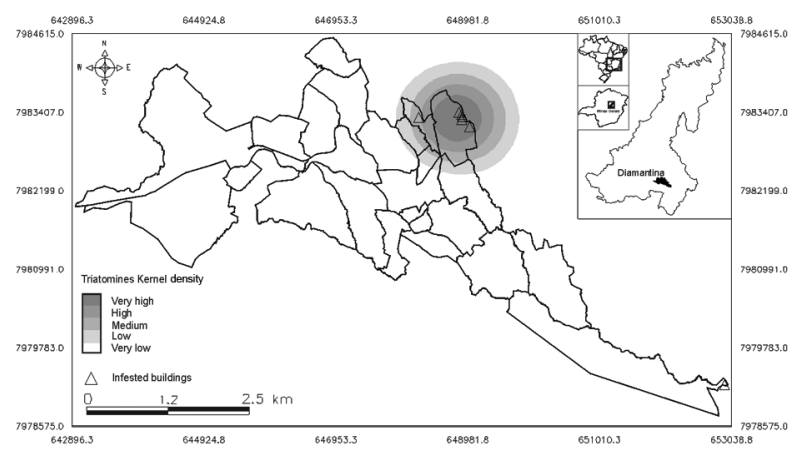

B

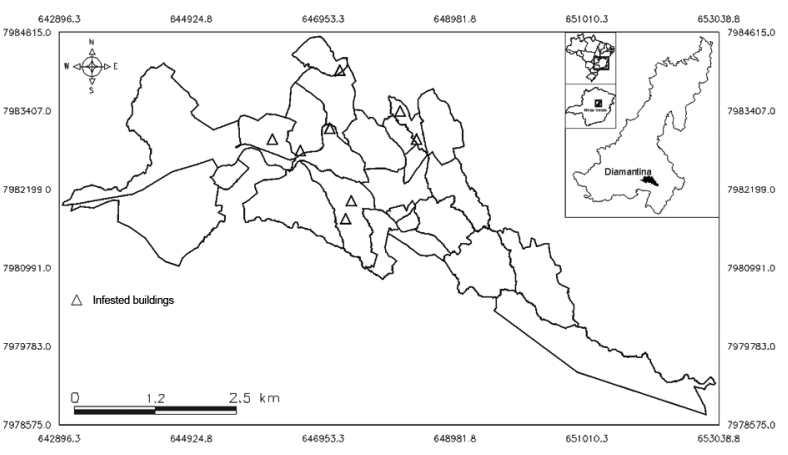

D

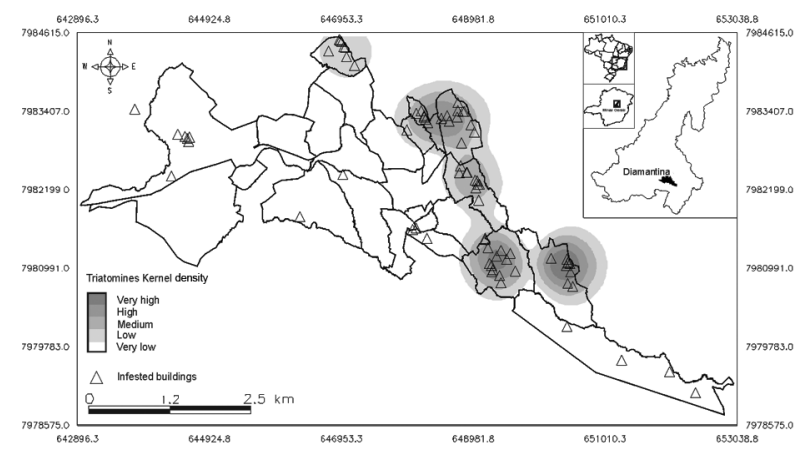

Fig. 3: spatial distribution of triatomines captured in the city of Diamantina, state of Minas Gerais, Brazil, September 2011-August 2014. A: Panstrongylus geniculatus; B: Panstrongylus megistus; C: Triatoma arthurneivai; D: Triatoma vitticeps.

The spatial distribution of infestation by $T$. vitticeps in Diamantina was clustered and was mainly observed in peripheral neighbourhoods. These areas represent the boundary between the urban area and the Cristais Mountains, a preserved area mainly covered by campos rupestres. This condition may explain the fact that domiciles infested by T. vitticeps were closer to open-fields than uninfested random points. The terrain in this area is irregular, exhibiting fissured rocks. Notably, Leite et al. (2010) observed that domiciliary infestation by $T$. vitticeps is associated with areas where the terrain is highly variable, in which crevices might be the shelter for triatomine hosts in ES.

Higher NDVI values close to $T$. vitticeps infested domiciles (even when those houses were far from forest fragments) might be associated with border areas with a low building density, so that circles around infested houses would include a smaller area lacking vegetation.

Although $P$. geniculatus is considered a sylvatic triatomine, it was observed colonising pigsties in Brazil (Valente et al. 1998) and was involved in oral acute Chagas disease urban outbreaks in Venezuela (Alarcón de Noya et al. 2010, Muñoz-Calderón et al. 2013) and vectorial transmission of $T$. cruzi in Peru (Vega et al. 2006). The high infection rates observed for this triatomine may be explained by its association with important hosts of T. cruzi, particularly armadillos (Chagas 1912, Martins et al. 1940, Barretto 1979, Alvarado-Otegui et al. 2012). Species distribution in Diamantina was more conspicuous in areas close to open-fields and forest fragments that may be the natural foci of these species.

$P$. megistus is the most important $T$. cruzi vector in the vast areas of Brazil. In the urban area of Diamantina, this triatomine was randomly distributed in areas with low vegetation cover as estimated by NDVI values. However, it is worth remarking that isolated patches with high NDVI values were found next to houses infested by $P$. megistus. These patches may represent small forest fragments that would maintain the sylvatic foci of P. megistus, where adults could disperse from, as observed by Santos Jr et al. (2013), into other urban areas of Brazil. Flight represents the main dispersal mechanism for triatomines and, as observed for T. infestans and Triatoma sordida, these insects can easily span distances greater than $100 \mathrm{~m}$ (Schofield et al. 1991, 1992).

T. arthurneivai is a rarely captured species, reported only in areas covered by campos rupestres, located in the southern part of the Espinhaço Mountain Range (Lent \& Martins 1940, Dias et al. 2011). Based on its restricted distribution and singular characteristics of vegetation and relief, Dias et al. (2011) proposed that the Espinhaço Mountain Range is the endemic area of this triatomine. The present study results agreed with these previous observations; infestations by $T$. arthurneivai were clustered in hotspots of occurrence found near borders between the urban area and the Cristais Mountains, a segment of the Espinhaço Mountain range. 

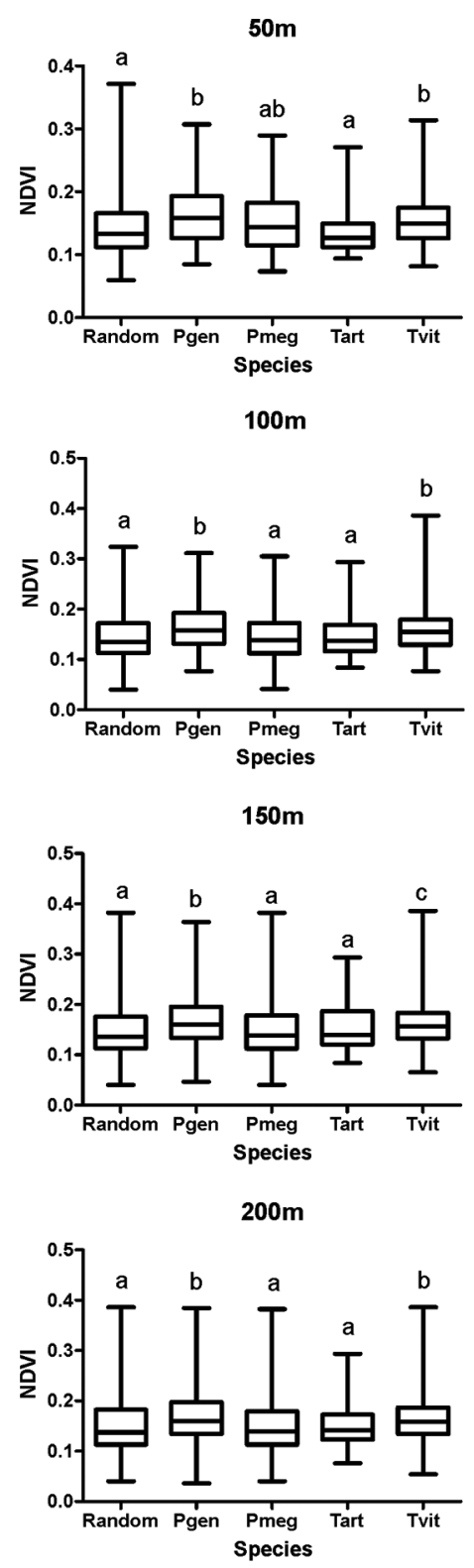

$250 \mathrm{~m}$

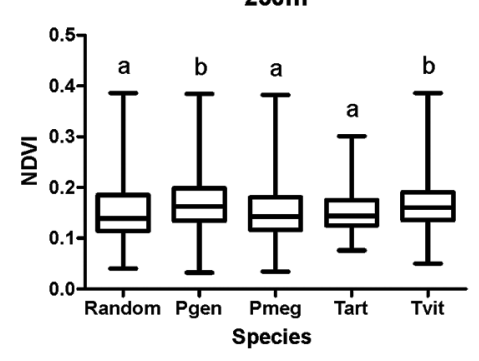

Fig. 4: normalized density vegetation index (NDVI) around triatomine-infested buildings and "uninfested" areas in the city of Diamantina, state of Minas Gerais, Brazil, according to radius surrounding infested and "uninfested" sites. Different letters represent significant statistical differences $(\mathrm{p} \leq 0.05)$ between groups in the KruskalWallis test. Pgen: Panstrongylus geniculatus; Pmeg: Panstrongylus megistus; random: randomized points in uninfested areas; Tart: Triatoma arthurneivai; Tvit: Triatoma vitticeps.
Despite the success in eliminating domestic populations of triatomines, the Chagas disease control services of Brazil face challenges in maintaining the entomologic surveillance. Although most triatomines captured in Diamantina domiciles have low colonisation capacity in houses, their high prevalence of trypanosome infections may represent a considerable risk for the transmission of T. cruzi to humans. Thus, in areas such as Diamantina, where there is a mosaic of urban areas and naturally preserved environments that may function as "dispersive islands", strengthening entomological surveillance efforts in these scenarios is needed.
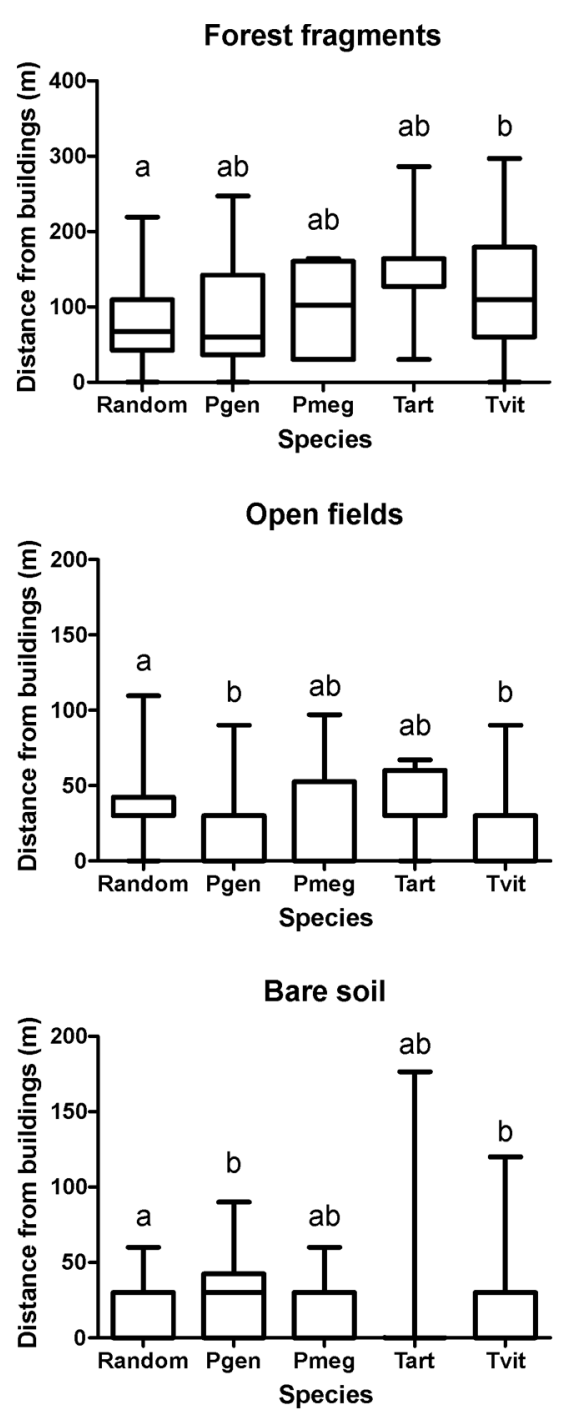

Fig. 5: distances from triatomine-infested buildings and "uninfested" points to areas with distinct land cover in the city of Diamantina, state of Minas Gerais, Brazil. Different letters represent significant statistical differences $(\mathrm{p} \leq 0.05)$ between groups in the Kruskal-Wallis test. Pgen: Panstrongylus geniculatus; Pmeg: Panstrongylus megistus; random: randomized points in uninfested areas; Tart: Triatoma arthurneivai; Tvit: Triatoma vitticeps. 


\section{ACKNOWLEDGEMENTS}

To Adílson dos Santos, Edenílson Oliveira, Helder Souza, Josimar Ferreira, and Mauro Machado, for support in data collection, and to Kelly McMaster, for English revision.

\section{REFERENCES}

Abad-Franch F, Diotaiuti L, Gurgel-Gonçalves R, Gürtler RE 2013. Certifying the interruption of Chagas disease transmission by native vectors: cui bono? Mem Inst Oswaldo Cruz 108: 251-254.

Alarcón de Noya B, Díaz-Bello Z, Colmenares C, Ruiz-Guevara R, Mauriello L, Zavala-Jaspe R, Suarez JA, Abate T, Naranjo L, Paiva M, Rivas L, Castro J, Márques J, Mendoza I, Acquatella H, Torres J, Noya O 2010. Large urban outbreak of orally acquired acute Chagas disease at a school in Caracas, Venezuela. J Infect Dis 201: 1308-1315.

Alvarado-Otegui JA, Ceballos LA, Orozco MM, Enriquez GF, Cardinal MV, Cura C, Schijman AG, Kitron U, Gürtler RE 2012. The sylvatic transmission cycle of Trypanosoma cruzi in a rural area of the humid Chaco of Argentina. Acta Trop 124: 79-86.

Alvares CA, Stape JL, Sentelhas PC, Gonçalves JLM, Sparovek G 2013. Köppen's climate classification map for Brazil. Meteorol Z 22: 711-728.

Barretto MP 1979. Epidemiologia. In Z Brener, Z Andrade (orgs.), Trypanosoma cruzi e doença de Chagas, Guanabara-Koogan, Rio de Janeiro, p. 89-151.

Câmara G, Souza RCM, Freitas UM, Garrido J 1996. SPRING: integrating remote sensing and GIS by object-oriented data modelling. Comput Graphics 20: 395-403.

Carvalho DB, Almeida CE, Rocha CS, Gardim S, Mendonça VJ, Ribeiro AR, Alves ZCPVT, Ruellas KT, Vedoveli A, Rosa JA 2014. A novel association between Rhodnius neglectus and the Livistona australis palm tree in an urban center foreshadowing the risk of Chagas disease transmission by vectorial invasions in Monte Alto city, São Paulo, Brazil. Acta Trop 130: 35-38.

Chagas C 1912. Sobre um Trypanosoma do tatú, Tatusia novencincta, transmitido pelo Triatoma geniculata Latr (1811). Possibilidade de ser o tatú um depositário do Trypanosoma cruzi no mundo exterior. Nota prévia. Braz Med 26: 305-336.

Chavez Jr PS 1988. An improved dark-object subtraction technique for atmospheric scattering correction of multispectral data. Remote Sens Environ 24: 459-479.

Costa FN 2005. Campos rupestres. In AC Silva, LCVSF Pedreira, PA Almeida-Abreu (orgs.), Serra do Espinhaço Meridional: paisagens e ambientes, O Lutador, Belo Horizonte, p. 139-145.

Coura JR 2007. Chagas disease: what is known and what is needed - A background article. Mem Inst Oswaldo Cruz 102 (Suppl. I): 113-122.

Diamantina 2009. Plano diretor participativo do municipio de Diamantina/MG. Documento técnico. Available from: camaradiamantina. com.br/PlanoDiretor/DI_relatório técnico_volume I_09-08-11.pdf.

Dias JCP 2007. Southern Cone Initiative for the elimination of domestic populations of Triatoma infestans and the interruption of transfusional Chagas disease. Historical aspects, present situation, and perspectives. Mem Inst Oswaldo Cruz 102 (Suppl. I): 11-18.

Dias JCP, Feitosa VR, Ferraz Filho AN, Rodrigues VLC, de Alencar SA, Sessa PA 1989. Fonte alimentar e potencial vetorial de Triatoma vitticeps (Stål, 1859) com relação à doença de Chagas humana no estado do Espírito Santo, Brasil (Hemiptera, Reduviidae). Mem Inst Oswaldo Cruz 84 (Suppl. IV): 165-173.

Dias JCP, Loyola CCP, Brener S 1985. Doença de Chagas em Minas Gerais: situação atual e perspectivas. Rev Bras Malariol Doencas Trop 37: 7-28.
Dias JVL, Avelar BA, Cirqueira-Júnior H, Diotaiuti L, Pires HHR 2011. Capture of Triatoma arthurneivai (Hemiptera: Reduviidae) using a new luminous trap in Southeast Brazil. Rev Soc Bras Med Trop 44: 774-776.

Dixon PM 2002. Ripley's K-function. In AH El-Shaarawi, WW Piegorsch (orgs.), Encyclopedia of environmetrics. Available from: biostat.umn.edu/ dipankar/pubh8472/RipleysK.pdf.

dos Santos A, Letro RB, Bem VAL, Azeredo BV, Coelho GL, Diotaiuti L, Machado-de-Assis GF, Lana M 2014. Evaluation of the Chagas disease control program in Açucena municipality, Rio Doce Valley, state of Minas Gerais, Brazil. Rev Soc Bras Med Trop 47: 186-192.

dos Santos CB, Ferreira AL, Leite GR, Ferreira GEM, Rodrigues AAF, Falqueto A 2005. Peridomiciliary colonies of Triatoma vitticeps (Stål, 1859) (Hemiptera, Reduviidae, Triatominae) infected with Trypanosoma cruzi in rural areas of the state of Espírito Santo, Brazil. Mem Inst Oswaldo Cruz 100: 471-473.

dos Santos CB, Leite GR, Ferreira GEM, Ferreira AL 2006a. Infecção natural de Triatoma vitticeps (Stål, 1859) por flagelados morfologicamente semelhantes ao Trypanosoma cruzi no estado do Espírito Santo. Rev Soc Bras Med Trop 39: 89-91.

dos Santos CB, Leite GR, Sessa PA, Falqueto A 2006b. Dynamics of feeding and defecation in Triatoma vitticeps (Stål, 1859) (Hemiptera, Reduviidae, Triatominae) and its potential in the transmission of Trypanosoma cruzi. Mem Inst Oswaldo Cruz 101: 543-546.

Eiten G 1992. Natural Brazilian vegetation types and their causes. An Acad Bras Cienc 64: 35-65.

Gatrell AC, Bailey TC, Diggle PJ, Rowlingson BS 1996. Spatial point pattern analysis and its application in geographical epidemiology. Trans Inst Br Geogr 21: 256-274.

Gonçalves TCM, de Oliveira E, Dias LS, Almeida MD, Nogueira WO, Pires FDA 1998. An investigation on the ecology of Triatoma vitticeps (Stål, 1859) and its possible role in the transmission of Trypanosoma cruzi in the locality of Triunfo, Santa Maria Madalena municipal district, state of Rio de Janeiro, Brazil. Mem Inst Oswaldo Cruz 93: 711-717.

Gonçalves TCM, Rocha DS, Cunha RA 2000. Feeding patterns of Triatoma vitticeps in the state of Rio de Janeiro, Brazil. Rev Saude Publica 34: 348-352.

Gürtler RE, Cecere MC, Fernández MP, Vazquez-Prokopec GM, Ceballos LA, Gurevitz JM, Kitron U, Cohen JE 2014. Key sources habitats and potential dispersal of Triatoma infestans populations in northwestern Argentina: implications for vector control. PLoS Negl Trop Dis 8: e3238.

Guzman-Tapia Y, Ramírez-Sierra MJ, Dumonteil E 2007. Urban infestation by Triatoma dimidiata in the city of Mérida, Yucatán, México. Vector Borne Zoonotic Dis 7: 597-606.

Lagrotta MTF, Silva WC, Souza-Santos R 2008. Identification of key areas for Aedes aegypti control through geoprocessing in Nova Iguaçu, Rio de Janeiro state, Brazil. Cad Saude Publica 24: 70-80.

Leite GR, Santos CB, Falqueto A 2010. Influence of the landscape on dispersal of sylvatic triatomines to anthropic habitats in the Atlantic Forest. J Biogeogr 38: 651-663.

Lent H, Martins AV 1940. Estudos sobre os triatomídeos do estado de Minas Gerais, com descrição de uma espécie nova. Rev Entomol 11: $877-886$.

Lorosa ES, Santos CM, Jurberg J 2008. Foco da doença de Chagas em São Fidélis, no estado do Rio de Janeiro. Rev Soc Bras Med Trop 41: 419-420.

Lorosa ES, Valente MVMP, Cunha V, Lent H, Jurberg J 2003. Foco de doença de Chagas em Arcádia, estado do Rio de Janeiro, Brasil. Mem Inst Oswaldo Cruz 98: 885-887. 
Maeda MH, Knox MB, Gurgel-Gonçalves R 2012. Occurrence of synanthropic triatomines (Hemiptera: Reduviidae) in the Federal District of Brazil. Rev Soc Bras Med Trop 45: 71-76.

Martins AV, Versiani V, Tupinambá A 1940. Estudos sobre a tripanosomiase americana em Minas Gerais, Brasil. Mem Inst Oswaldo Cruz 35: 285-301.

MP/IBGE - Ministério do Planejamento, Orçamento e Gestão/Instituto Brasileiro de Geografia e Estatística 2014. Resolução $n^{\circ} 2$, Diário Oficial da República Federativa do Brasil, Brasília, 28 agosto 2014, Seção I, n 165, p. 98-115.

MS/SUCAM/DIDOCh - Ministério da Saúde/Superintendência de Campanhas de Saúde Pública/Divisão de Doença de Chagas 1980. Inquérito sorológico: prevalência por municipio, Centro de Documentação do Ministério da Saúde, Brasília.

Muñoz-Calderón A, Díaz-Bello Z, Valladares B, Noya O, López MC, Alarcón de Noya B, Thomas MC 2013. Oral transmission of Chagas disease: typing of Trypanosoma cruzi from five outbreaks occurred in Venezuela shows multiclonal and common infections in patients, vectors, and reservoirs. Infect Genet Evol 17: 113-122.

OPS - Organización Panamericana de la Salud 1993. Taller de definición de indicadores para la certificación de la eliminación de Triatoma infestans. Rev Soc Bras Med Trop 26: 51-54.

Rassi Jr A, Rassi A, Marin-Neto JA 2010 . Chagas disease. Lancet 375: 1388-1402.

Reis RQ, Caran GF, Dias JVL, Pires HHR, Diotaiuti LG, Martins HR 2013. Caracterização genética de Trypanosoma cruzi de triatomíneos naturalmente infectados oriundos de municípios do Vale do Jequitinhonha, Minas Gerais, Brasil. Anais da II Semana da Integração do Ensino, Pesquisa e Extensão da Universidade Federal dos Vales do Jequitinhonha e Mucuri. Available from: sgea.ufvjm.edu. br/sintegra2013/files/publico/Anais_II_Sintegra_2013.pdf.

Ribeiro Jr G, Gurgel-Gonçalves R, Reis RB, Santos CGS, Amorim A, Andrade SG, Reis MG 2015. Frequent house invasion of Trypanosoma cruzi-infected triatomines in a suburban area of Brazil. PLoS Negl Trop Dis 9: e0003678.

Rodrigues VLCC, Pauliquevis Jr C, Silva RA, Wanderley DMV, Guirardo MM, Rodas LAC, Casanova C, Pachioni ML, Souza WA, Costa AJB, Baitelo D, Tonietti VLB 2014. Colonization of palm trees by Rhodnius neglectus and household and invasion in an urban area, Araçatuba, São Paulo state, Brazil. Rev Inst Med Trop Sao Paulo 56: 213-218.
Sangenis LHC, Saraiva RM, Georg I, Castro L, Lima VS, Roque ALR, Xavier SCC, Santos LC, Fernandes FA, Sarquis O, Lima MM, Carvalho-Costa FA, Bóia MN 2015. Autochthonous transmission of Chagas disease in Rio de Janeiro state, Brazil: a clinical and eco-epidemiological study. BMC Infect Dis 15: e4.

Santana KSO, Bavia ME, Lima AD, Guimarães ICS, Soares ES, Silva MMN, Mendonça J, Martin MS 2011. Spatial distribution of triatomines (Reduviidae: Triatominae) in urban areas of the city of Salvador, Bahia, Brazil. Geospat Health 5: 199-203.

Santos Jr JE, Viola MG, Lorosa ES, Machado EMM, Ruas-Neto AL, Corseuil E 2013. Evaluation of natural foci of Panstrongylus megistus in a forest fragment in Porto Alegre, state of Rio Grande do Sul, Brazil. Rev Soc Bras Med Trop 46: 575-583.

Schofield CJ, Lehane MJ, McEwen P, Catalá SS, Gorla DE 1991. Dispersive flight by Triatoma sordida. Trans $R$ Soc Trop Med Hyg 85: 676-678.

Schofield CJ, Lehane MJ, McEwen P, Catalá SS, Gorla DE 1992. Dispersive flight by Triatoma infestans under natural climatic conditions in Argentina. Med Vet Entomol 6: 51-56.

Souza RCM, Diotaiuti L, Lorenzo MG, Gorla DE 2010. Analysis of the geographical distribution of Triatoma vitticeps (Stål, 1859) based on data of species occurrence in Minas Gerais, Brazil. Infect Genet Evol 10: 720-726.

UNESCO - United Nations Educational, Scientific, and Cultural Organization 2000. World Heritage Committee 2000. Convention concerning the protection of the world cultural and natural heritage - report. Available from: whc.unesco.org/archive/1999/whc99-conf209-22e.pdf.

Valente VC, Valente SA, Noireau F, Carrasco HJ, Miles MA 1998. Chagas disease in the Amazon Basin: association of Panstrongylus geniculatus (Hemiptera: Reduviidae) with domestic pigs. $J$ Med Entomol 35: 99-103.

Vasconcelos MF 2011. O que são campos rupestres e campos de altitude nos topos de montanha do leste do Brasil? Revista Brasil Bot 34: 241-246.

Vega S, Mendoza A, Cabrera R, Cáceres AG, Campos E, Ancca J, Pinto J, Torres S, Cabrera D, Yale G, Cevallos R, Náquira C 2006. Primer caso de enfermedad de Chagas aguda en la Selva Central del Perú: investigación de colaterales, vectores y reservorios. Rev Peru Med Exp Salud Publica 23: 288-292.

Vieira JPG, Souza MJH, Teixeira JM, Carvalho FP 2010. Estudo da precipitação mensal durante a estação chuvosa em Diamantina, Minas Gerais. Rev Bras Eng Agric Ambient 14: 762-767. 